\title{
Delayed Extradural Hematoma after Evacuation of Contralateral Acute Extradural Hematoma
}

\author{
Majid Anwer ${ }^{1, *} \quad$ Atique Ur Rehman ${ }^{1} \quad$ Farheen Ahmed ${ }^{2} \quad$ Satyendra Kumar ${ }^{1} \quad$ Md Masleh Uddin $^{1}$ \\ ${ }^{1}$ Department of Trauma Surgery and Critical Care, \\ Medaz Hospital, Patna, India \\ ${ }^{2}$ Department of Anesthesiology \& Critical Care, Indira Gandhi \\ Institute Of Medical Sciences, Sheikhpura, Patna, India \\ Address for correspondence Majid Anwer, MCh, \\ Department of Trauma Surgery and Critical Care, Medaz Hospital, \\ Biscouman Golambar, Patna 800007, India \\ (e-mail: majidanwer1987@gmail.com).
}

Indian J Neurotrauma:2021;18:59-62

\begin{abstract}
Keywords

- extradural hematoma

- intracranial pressure

- skull fracture

- head injury

- Glasgow Coma Scale

Introduction Traumatic head injury with extradural hematoma (EDH) is seen in $2 \%$ of patients. Development of EDH on the contralateral side is an uncommon complication that has been reported in various case reports.

Methods We report here a case of an 18-year-old male who had a road traffic injury. He was diagnosed as a case of left-sided large frontotemporoparietal acute extradural bleed with a mass effect toward the right side. He was managed with urgent craniotomy and evacuation of hematoma. A noncontrast computed tomography (NCCT) scan performed 8 hours after postoperative period showed a large frontotemporoparietal bleed on the right side with a mass effect toward the left side. He was again taken to the operating room and right-sided craniotomy and evacuation of hematoma were performed. A postoperative NCCT scan revealed a resolved hematoma. The patient made a complete recovery in the postoperative period and is doing well.

Conclusion Delayed onset epidural hematoma is diagnosed when the initial computed tomography (CT) scan is negative or is performed early and when late CT scan performed to assess clinical or ICP deterioration shows an EDH. The diagnosis of such a condition requires a high index of suspicion based on the mechanism of injury along with fracture patterns. Additionally, change in pupillary size, raised intracranial pressure, and bulging of the brain intraoperatively are additional clues for contralateral bleeding. Neurologic deterioration may or may not be associated with delayed EDH presentation. An early postoperative NCCT scan within 24 hours is recommended to detect this complication with or without any neurologic deterioration.
\end{abstract}

\section{Introduction}

Traumatic brain injury with extradural hematoma (EDH) is seen in around $2 \%$ of patients. ${ }^{1}$ EDHs are usually associated with underlying skull fracture in around $75 \%$ of the population. ${ }^{1}$ EDH after traumatic brain injury is a surgical emergency. Timely diagnosis and its management has led to decreased

\footnotetext{
* The author has completed his M.Ch. in Trauma Surgery and Critical Care from JPN Apex Trauma Center, AIIMS, New Delhi, and is working as consultant Trauma Surgery at Medaz Hospital, Patna
}

published online

September 2, 2020
DOI https://doi.org/

$10.1055 / \mathrm{s}-0040-1713722$

ISSN 0973-0508. mortality from over 30\% in 1970s to almost 0\% nowadays. ${ }^{2}$ Surgical evacuation of hematoma after craniotomy remains the treatment of choice wherever indicated. Development of EDH on the contralateral side is an uncommon complication that has been reported in various case reports. It can present as a delayed complication ${ }^{3,4}$ or can develop intraoperatively. ${ }^{5,6}$ Missing a delayed finding of EDH on the contralateral side can have devastating complications for the patient. We describe the case of a young male with road traffic injury who developed postoperative contralateral EDH.

(C)2020. Neurotrauma Society of India.

This is an open access article published by Thieme under the terms of the Creative Commons Attribution-NonDerivative-NonCommercial-License, permitting copying and reproduction so long as the original work is given appropriate credit. Contents may not be used for commercial purposes, or adapted, remixed, transformed or built upon. (https://creativecommons.org/licenses/by-nc-nd/4.0/).

Thieme Medical and Scientific Publishers Pvt. Ltd. A-12, 2nd Floor, Sector 2, Noida-201301 UP, India 


\section{Case Report}

An 18-year-old male presented to the emergency with road traffic injury. The patient was on a two-wheeler and had a head-on collision with a four-wheeler. He was primarily treated at local hospital and then brought here 4 hours after the injury. He had a positive history of loss of consciousness, one episode of vomiting, and bleeding from the nose. Neurologic examination revealed a withdrawal response to painful stimuli in the bilateral upper and lower limbs along with pupillary anisocoria (left larger than the right). On primary survey, he had a pulse rate of 80 beats per minute and blood pressure of 140/90 mm Hg. He was intubated, sedated, and put on mechanical ventilation. A noncontrast computed tomography (NCCT) of the head and C-spine was advised. On NCCT of the head, there was a large left-sided frontotemporoparietal acute extradural bleed with a mass effect toward the right side ( - Fig. 1.) There was fracture of the left and right temporal bone also. The patient was taken to the operation room (OR) where left-sided frontotemporoparietal craniotomy was performed. There was a large EDH with active bleeding from a branch of the middle meningeal artery ( - Fig. 2). The hematoma was scooped out, and the bleeding vessel was secured. Right after removal, the brain got relaxed with no obvious bulge. Dural hitching was performed, and the bone was placed back. After that, the patient was shifted to the intensive care unit (ICU) where he was sedated, paralyzed, and put on mechanical ventilation. His postoperative neurologic examination revealed eye opening to painful stimuli and the ability to localize painful stimuli in the bilateral upper and lower limbs. The pupil was of bilateral normal

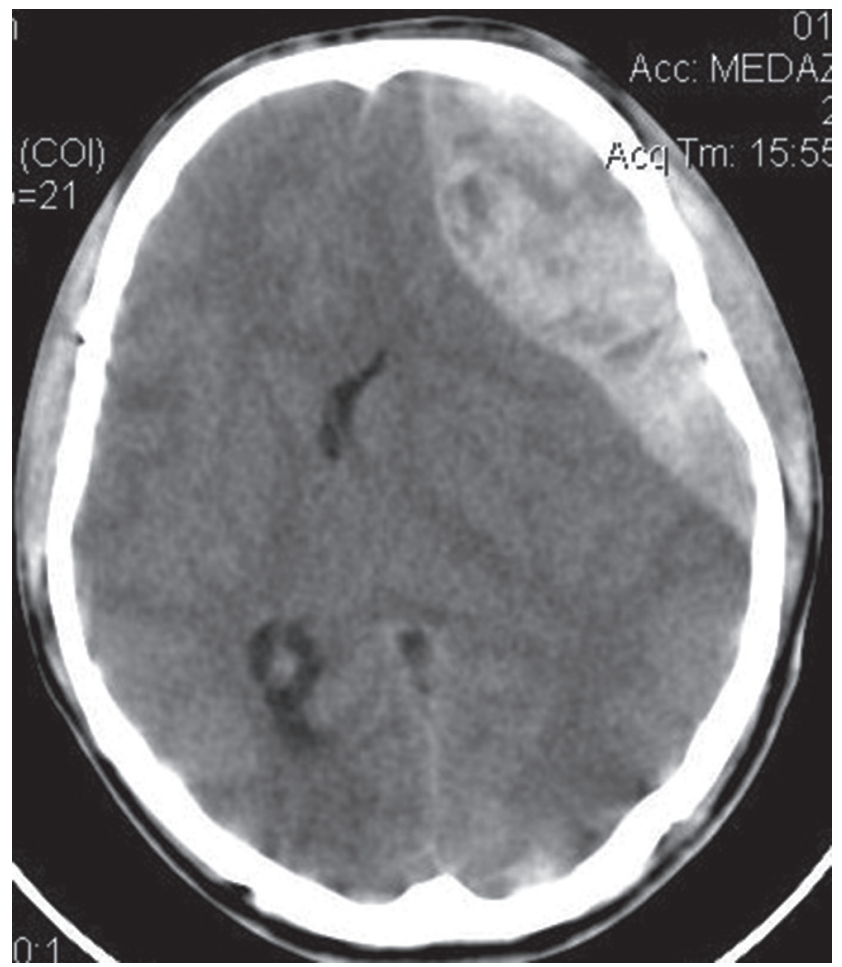

Fig. 1 Noncontrast computed tomography scan of the head showing a large left extradural hematoma with a mass effect. The right linear temporal bone fracture is also visible. size and reacted to light. A postoperative CT performed after 8 hours revealed a large right-sided extradural bleed with a mass effect ( - Fig. 3). The patient was again taken to the OR

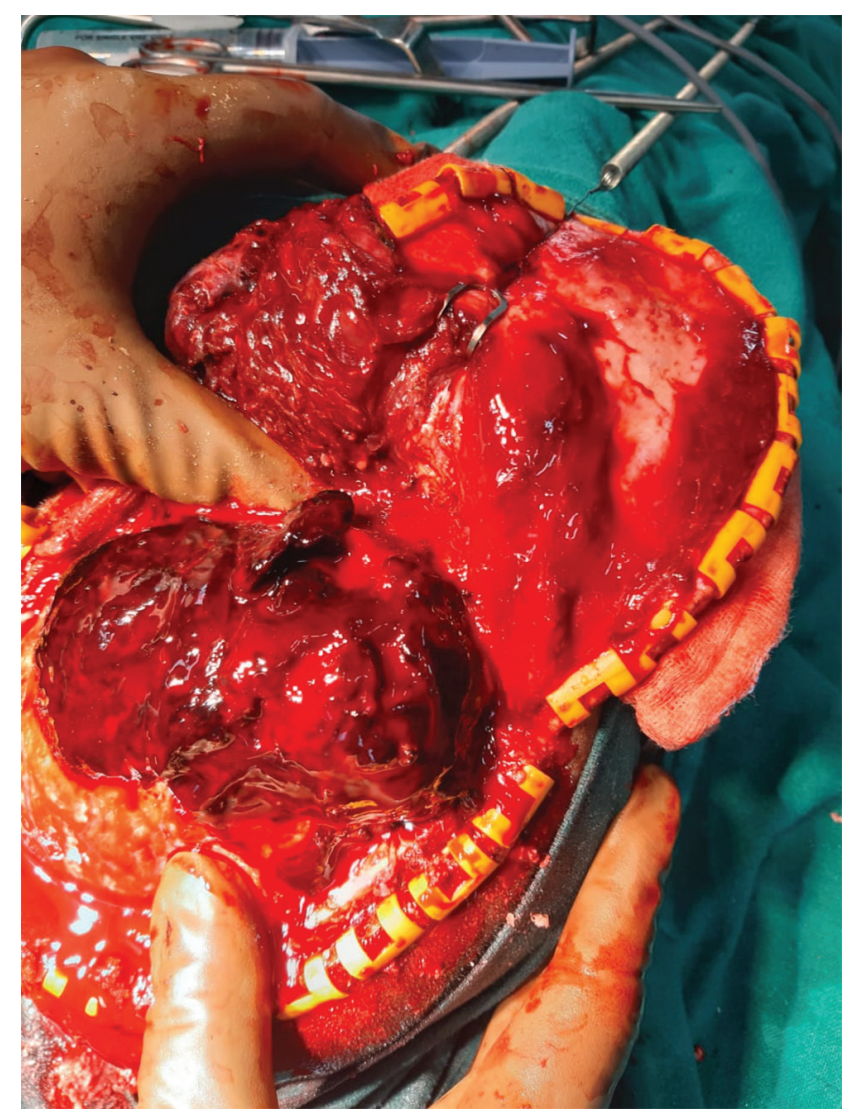

Fig. 2 Intraoperative image showing a large extradural hematoma.

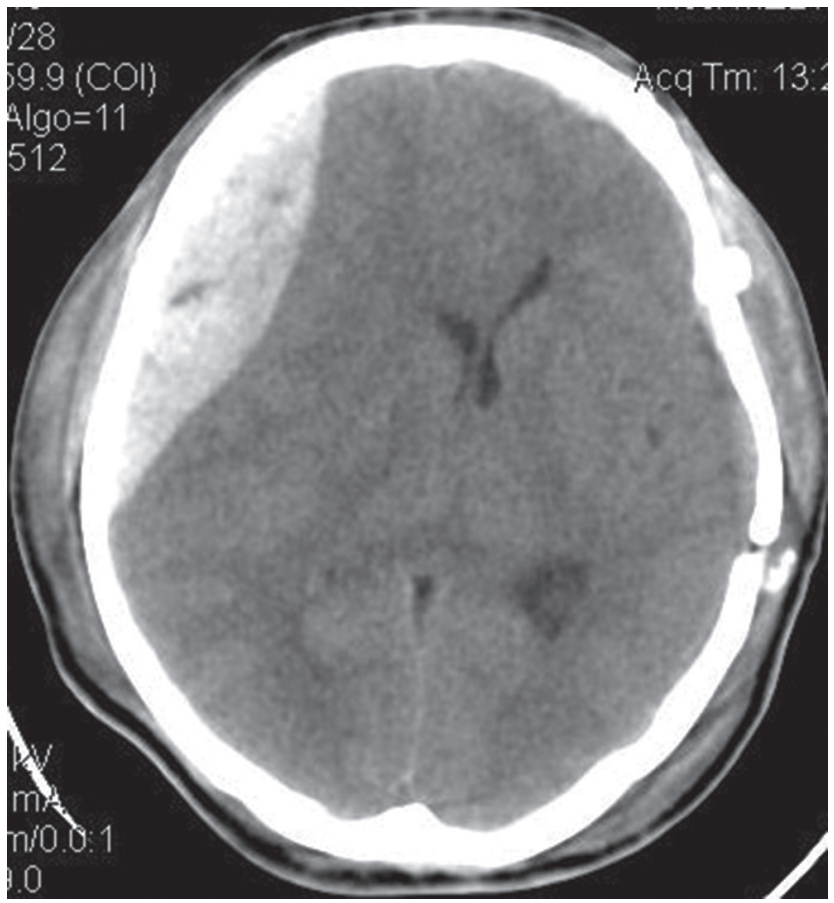

Fig. 3 Noncontrast computed tomography scan of the head showing a large extradural hematoma on the right side with a mass effect. Left-sided craniotomy site is also seen here. 
where right frontotemporoparietal craniotomy and evacuation of hematoma were performed. Again, the culprit was bleed from the middle meningeal artery $(\boldsymbol{\sim}$ Fig. 4 ). After securing the bleeding vessel and dural hitching, the bone was placed back. In the postoperative period, the patient was kept in the ICU on ventilator support. He was extubated the next day. He regained his consciousness with spontaneous eye opening and was confused but obeyed commands, moving all four limbs equally. His Glasgow Coma Scale (GCS) score improved from 6 (E1VNTM4) in the preoperative period to 14 (E4V4M6) on the postoperative day 3. His postoperative NCCT of the head showed resolved hematoma (-Fig. 5). Bilateral drains were removed on postoperative day 3 . He was shifted to the ward from where he was discharged after 11 days. He is coming for regular outpatient department follow-up and is doing well.

\section{Discussion}

Traumatic brain injury with EDH is an emergency. An NCCT scan is used to diagnose such a condition in the immediate postadmission period. Delayed onset epidural hematoma is diagnosed when the initial CT scan is negative or is performed early and when late CT scan performed to assess clinical or low intracranial pressure (ICP) deterioration shows an EDH. ${ }^{13,4,6}$ The diagnosis of such condition requires a high index of suspicion based on the mechanism of injury along with fracture patterns. ${ }^{7}$ Additionally, change in pupillary

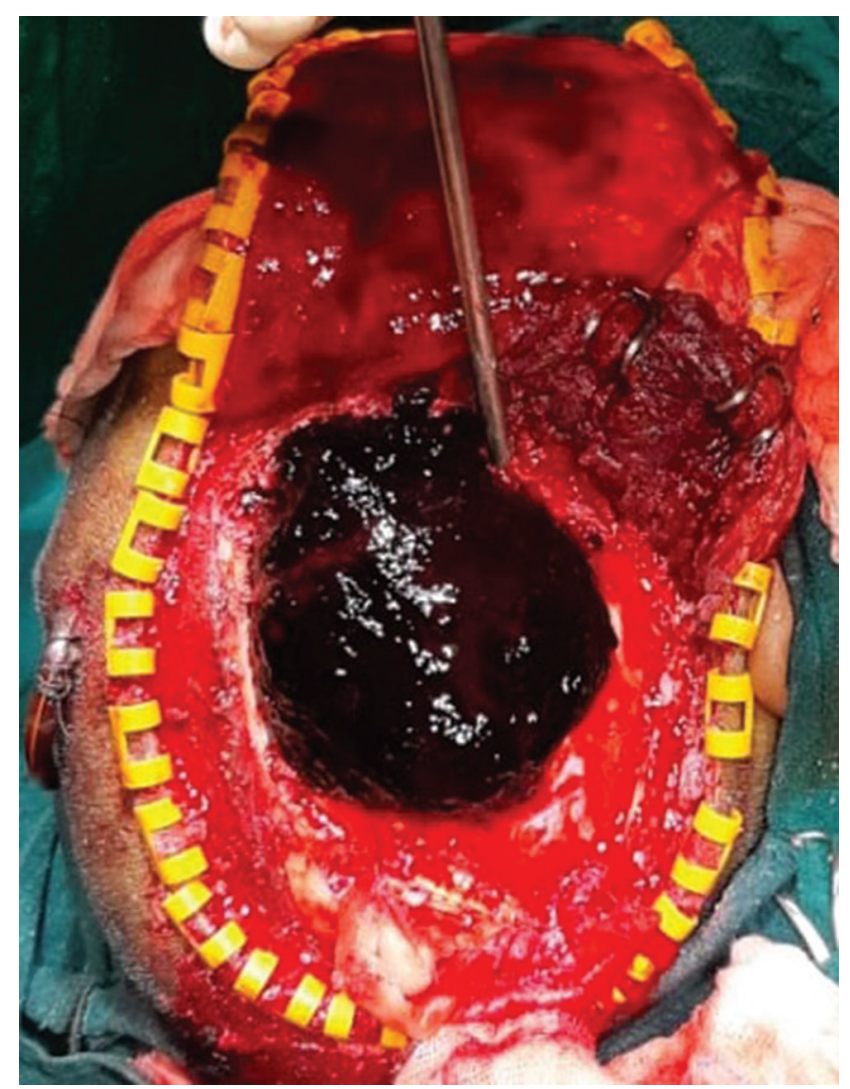

Fig. 4 Intraoperative image showing a large extradural hematoma on the right side. size, raised ICP, and bulging of the brain intraoperatively are additional clues for contralateral bleeding. ${ }^{1,48}$ Neurologic deterioration may or may not be associated with delayed EDH presentation. ${ }^{3}$ As was in our case, there was no deterioration in the GCS score in the postoperative period. An early postoperative NCCT scan within 24 hours has been suggested to detect this complication with or without any neurologic deterioration.

The underlying pathophysiology for the development of contralateral EDH is loss of tamponade effect on the dura after the evacuation of hematoma. ${ }^{1,6,9}$ The tamponade effect prevents the bleeding from the ruptured middle meningeal artery associated with a skull fracture. ${ }^{9}$ Any decompressive craniectomy performed for subdural hematoma, contusion, or evacuation of EDH causes the ICP to go down, and the opposite dura gets separated from the calvaria. There is disturbance in the equilibration in the brain and the loss of hemostatic effect of ICP. ${ }^{3}$ Rapid correction of hypotension, high blood pressure, and low ICP favors EDH at the fractured site. $^{3}$ The possible cause in our case could be the shift of the brain toward the operated site after evacuation of acute EDH. This would have caused enough space for the blood to collect in the contralateral extradural space. The triggering event was the associated temporal bone fracture. Gregori et $\mathrm{al}^{4}$ performed a literature review and compiled a list of 28 such cases in the past. Our case is 29th of such cases where the patient developed delayed EDH after 8 hours and was operated twice. The majority of the victims were males (88.2\%), with a median age of 25 years. Mortality rate was $5 / 29$ (17.24\%). Survival rate was 24/29 (82.75\%), with half of such patients having good recovery and half having mild-to-poor recovery. ${ }^{4}$

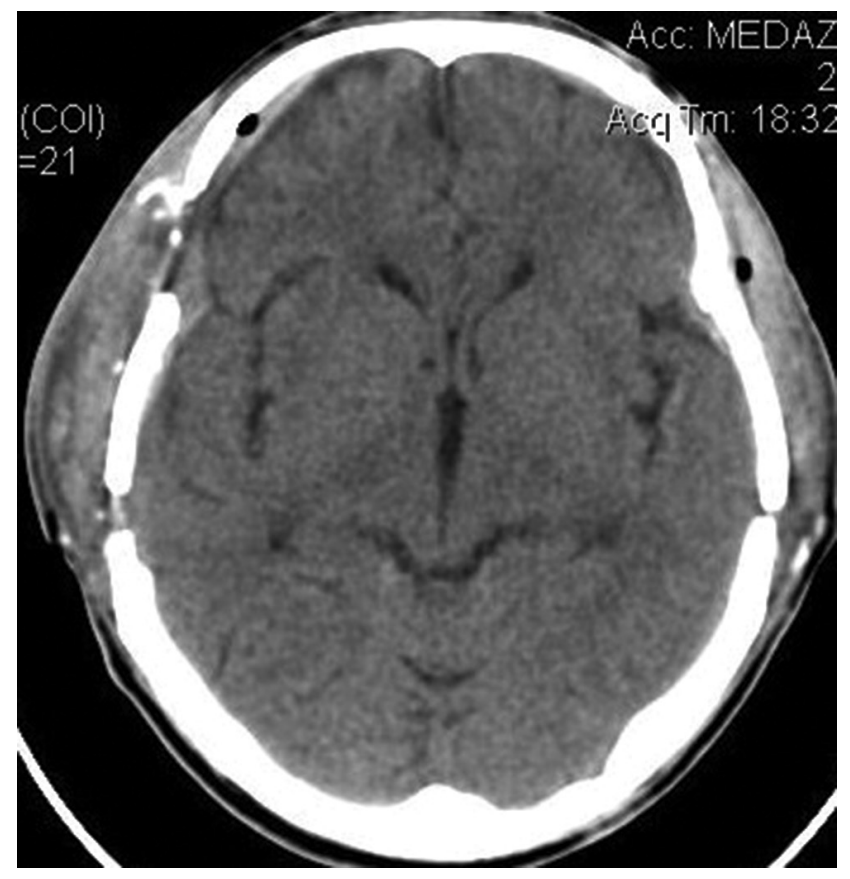

Fig. 5 Bilateral extradural hematoma operated with resolved hematoma. Bilateral craniotomy site is also visible. 


\section{Conclusion}

Prognosis of such condition is fair if the complication is identified early and surgical intervention is started. Late diagnosis can lead to a high mortality rate. ${ }^{4}$ A high index of suspicion based on the presence of intraoperative bulge, contralateral fracture, and early postoperative CT scan help in the early diagnosis of such patients. In our case, the patient had a complete recovery of consciousness and sensorimotor functions.

\section{Funding}

None.

\section{Conflict of Interest}

None declared.

\section{References}

1 Borovich B, Braun J, Guilburd JN, et al. Delayed onset of traumatic extradural hematoma. J Neurosurg 1985;63(1):30-34

2 Cheung PSY, Lam JMY, Yeung JHH, Graham CA, Rainer TH. Outcome of traumatic extradural haematoma in Hong Kong. Injury 2007;38(1):76-80

3 Feuerman T, Wackym PA, Gade GF. Lanman T, Becker D, Intraoperative development of contralateral epidural hematoma during evacuation of traumatic extraaxial hematoma. Neurosurgery 1988;23(4):480-484

4 Gregori F, Santoro G, Mancarella C, Piccirilli M, Domenicucci M. Development of a delayed acute epidural hematoma following contralateral epidural hematoma evacuation: case report and review of literature. Acta Neurol Belg 2019;119(1):15-20

5 Kostić A, Veselinović A, Nikolov V, Stefanović I, Mitić R, Radisavljević M. A combination of acute and delayed contralateral epidural hematoma. Srp Arh Celok Lek 2018;146(3-4): 193-196

6 Nadig AS, King AT. Traumatic extradural haematoma revealed after contralateral decompressive craniectomy. $\mathrm{Br} J$ Neurosurg 2012;26(6):877-879

7 Sharma A, Sharma A, Dewan Y. Intraoperative contralateral extradural hematoma during evacuation of traumatic acute extradural hematoma. Rom Neurosurg 2015;29(3):377-381

8 Singh M, Ahmad FU, Mahapatra A. Intraoperative development of contralateral extradural hematoma during evacuation of traumatic acute subdural hematoma: a rare cause of malignant brain bulge during surgery. Indian J Neurotrauma 2005;2(2):139-140

9 Talbott JF, Gean A, Yuh EL, Stiver SI. Calvarial fracture patterns on CT imaging predict risk of a delayed epidural hematoma following decompressive craniectomy for traumatic brain injury. Am J Neuroradiol 2014;35(10):1930-1935 